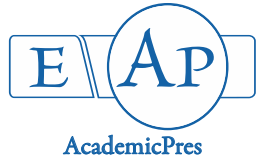

\title{
Palynological Studies of Three Taxa and One F1 Hybrid in the Genus Talinum Adans
}

\author{
Oluwabunmi O. AROGUNDADE*, Hameedat O. LAWAL \\ Obafemi Awolowo University, Department of Botany, Ile-Ife, Osun State, \\ Nigeria; oluwabunmiarogundade@gmail.com (" correspondingauthor); lawalhameedatopeyemi@gmail.com
}

\begin{abstract}
Acetolysed pollen grains of Talinum paniculatum (Jacq.) Gaertn., Talinum triangulare (Jacq.) Willd. pink petals, Talinum triangulare (Jacq.) Willd. white petals and Talinum triangulare (Jacq.) Willd. pink and white petals F1 hybrid were studied in order to document their morphological structures and ascertain features of taxonomic significance among them. All the taxa have generic features which support their classification as a genus as well as distinct features which ascertain their individuality. Generic features include monad pollen unit, acolpate and monocolpate pollen grains as well as circular and ovate pollen shapes. The delimiting features include additional dyads pollen units in T. triangulare white petal and the F1 hybrid of $T$. triangulare pink and white petals, quadrangular pollen shape in T. paniculatum, bicolpate pollen grain in the $\mathrm{F} 1$ hybrid, tricolpate pollens in T. triangulare white petal and T. paniculatum, tetracolpate pollens in T. triangulare pink petal and T. paniculatum and pentacolpate pollen grains in T.paniculatum only. The shape of the pores in T.paniculatum also separated it from the varieties and hybrid of T. triangulare. Based on the pollen size, the pollens of T.paniculatum are Media $(25-50 \mu \mathrm{m})$ while those of the two varieties of $T$. triangulare and their F1 hybrid are Magna $(50-100 \mu \mathrm{m})$. The taxa of Talinum in this study can be separated based on their palynological features.
\end{abstract}

Keywords: acetolysis; aperturate; colpi; generic; hybrid; pollen grains; pollen units; Talinum

\section{Introduction}

The study of spores and pollen grains has provided a good number of palynological features which are important in the identification of plant species as well as inferring phylogenetic relationships among them (Edeoga et al., 1998; Simpson, 2010). Genus Talinum was formerly in the family Portulacaceae, which consist of about 50 species (Nyananyo and Olowokudejo, 1986) but molecular phylogenetic data supported its placement in the family Talinaceae (Nyffeler and Eggli, 2010). In West Africa and in Nigeria, only two species of Talinum were reported (Hutchinson and Dalziel, 1954; Wagner and Herbst, 2003).

The morphology of the members of the genus has been variously described (Ekpo et al., 2013; Nya and Eka, 2015). The embryology of some Talinum species has also been studied by some researchers (Nyananyo, 1992; Veselova $e t$ al., 2012). Phylogenetic relationship and intra-specific variation among ten accessions of $T$. triangulare was established by Swarna et al. (2015) using molecular descriptors. Brasileiro et al. (2016) gave a detailed report of the chemical compositions of Talinum triangulare extract and its cytotoxic activity as well as the anatomy of the plant. A chromosome number of $2 n=24$ was reported for genus Talinum by Nyananyo and Olowokudejo (1986).

The two species reported in West Africa and in Nigeria were included in this study. They are Talinum triangulare (Jacq.) Willd. also known as Talinum fruticosum (L.) Juss. and Talinum paniculatum (Jacq.) Gaertn. Two varieties of $T$. triangulare were identified as T. triangulare (pink petal) and T. triangulare (white petal). Crosses of these two varieties were carried out by Ozeigbe et al. (2012). This led to the production of the F1 hybrid which was included in this study. In the filament pigmentation of the $T$. triangulare variants, Oziegbe et al. (2012) reported an incomplete dominance of the deep pink petal colour over the white colour.

Palynological characters have been variously employed in the taxonomy of species of plants, forensic sciences, crime site detection and archaeology. They have been reported useful in the delimitation of closely related, sympatric species and valuable in phylogenetic inferences. (Nyananyo, 1992; Akinwusi and Illoh, 1996; Edeoga et al., 1998; Adedeji, 2005; Arogundade and Adedeji, 2009; Simpson, 2010). 
176

\section{Materials and Methods}

\section{Pollen grains collection}

The taxa used in this study are Talinum paniculatum (Jacq.) Gaertn., Talinum triangulare (Jacq.) Willd. pink petals, Talinum triangulare (Jacq.) Willd. white petals and Talinum triangulare (Jacq.) Willd. pink and white petals F1 hybrid. These four were cultivated behind the Department of Botany building, Obafemi Awolowo University, Ile-Ife, Osun State, Nigeria (N07³1.149' E004 o31.555'). Pollen grains were collected from fresh anthers of these taxa and were stored in absolute ethanol till they were acetolysed.

\section{Acetolysis}

The method of Erdtman (1960) was employed for acetolysing of the pollen grains with some modifications. The anthers already stored in absolute ethanol were macerated and centrifuged at the speed of 4,000 revolutions per minute for 10 minutes. The ethanol was poured off and glacial acetic acid was added to the sediment which was centrifuged again at the same speed as before. After this, the glacial acetic acid supernatant was poured off and Acetolysis mixture (sulphuric acid and acetic anhydride) was added. The tubes containing these mixtures were then placed in a water bath and heated from a temperature of $70{ }^{\circ} \mathrm{C}$ to boiling point with intermittent stirring. Centrifugation was done again and the acetolysis mixture was poured off. Glacial acetic acid was added next, centrifuged and it was poured off. Finally, distilled water was added to the sediment and was followed by another centrifugation. The water was later decanted and the acetolysed pollen grains were mounted in dilute glycerine solution for microscopic examination.

\section{Microscopy}

Observation of acetolysed pollen grains was made with the aid of Olympus XSZ-107BN light microscope. Pollen structure description was done according to Moore and Webb (1978) and Putt et al. (2007). 150 acetolysed pollen grains were selected randomly from each of the taxa and the following measurements were taken on them - the pollen diameter, pore diameter and pollen wall thickness. The number of pores and furrows on the pollens were also counted. The measurements were taken with the aid of an ocular micrometer inserted into the eyepiece of the microscope. The ocular readings were later converted into micrometre by multiplying them with an ocular constant which corresponds to the magnification at which they were taken. Photomicrographs of the acetolysed pollen grains were taken with the aid of an AmScope camera attached to the microscope.

\section{Data analysis}

The data (quantitative and qualitative) generated from this study were subjected to univariate and multivariate analysis. The mean values of each of the quantitative characters were calculated and subjected to Duncan Multiple Range Test (DMRT) for the mean separation. Both types of data, that is, the quantitative and qualitative data were coded and subjected to Single Linkage Cluster Analysis (SLCA) and Principal Components Analysis (PCA).

\section{Results}

Generally, the surfaces of the pollens are not spinulose and not reticulate. All the taxa have the two main apertures, furrows, also known as colpi and pores hence; they all have aperturate pollen grains. All the species are polyporate. The summaries of the quantitative features and the DMRT of the Talinum taxa is as shown on Table 1 while Table 2 shows the eigenvalue and the percentage of total variation accounted for by the first three components axes of ordination. Fig. 1 is the Single Linkage Cluster Analysis (SCLA) dendrogram of the taxa of Talinum studied, while Figs. 2 and 3 are the Principal Components Analysis showing the relationship of Talinum taxa based on ten quantitative and qualitative pollen characters. Figs. 4, 5, 6 and 7 are the pictorial representations of the different types of pollen encountered in the genus.

Table 1. Summary of quantitative characteristics and the Duncan grouping of the four taxa of Talinum studied based on their pollen grain attributes

\begin{tabular}{|c|c|c|c|c|}
\hline \multirow{2}{*}{ Talinum taxa } & \multicolumn{4}{|c|}{ Pollen Character } \\
\hline & Pollen Diameter $(\mu \mathrm{m})$ & Pore Diameter $(\mu \mathrm{m})$ & Pollen Wall Thickness ( $\mu \mathrm{m})$ & Number of Pores \\
\hline T.paniculatum & $(44.87 \pm 0.26) \mathrm{C}$ & $(13.82 \pm 0.15) \mathrm{A}$ & $(3.41 \pm 0.01) \mathrm{C}$ & $(5.51 \pm 0.07) \mathrm{C}$ \\
\hline T. triangulare pink petal & $(59.34 \pm 0.42) \mathrm{B}$ & $(9.44 \pm 0.12) \mathrm{C}$ & $(4.00 \pm 0.09) \mathrm{A}$ & $(12.71 \pm 0.11) \mathrm{B}$ \\
\hline T. triangulare white petal & $(61.52 \pm 0.54) \mathrm{A}$ & $(10.36 \pm 0.13) \mathrm{B}$ & $(3.71 \pm 0.06) \mathrm{B}$ & $(13.22 \pm 0.12) \mathrm{A}$ \\
\hline $\begin{array}{l}\text { T. triangulare pink and white } \\
\text { petal F1 hybrid }\end{array}$ & $(58.83 \pm 0.36) \mathrm{B}$ & $(10.45 \pm 0.11) \mathrm{B}$ & $(3.51 \pm 0.03) \mathrm{C}$ & $(13.47 \pm 0.11) \mathrm{A}$ \\
\hline
\end{tabular}

Table 2. Eigenvalue and the percentage of total variation accounted for by the first three components axes of ordination of the Talinum taxa.

\begin{tabular}{cccc}
\hline PC & Eigenvalue & \% Variance & Cummulative percentage \\
\hline 1 & 1.95181 & 61.636 & 61.636 \\
3 & 0.74129 & 23.409 & 85.045 \\
& 0.473568 & 14.955 & 100.00 \\
\hline
\end{tabular}




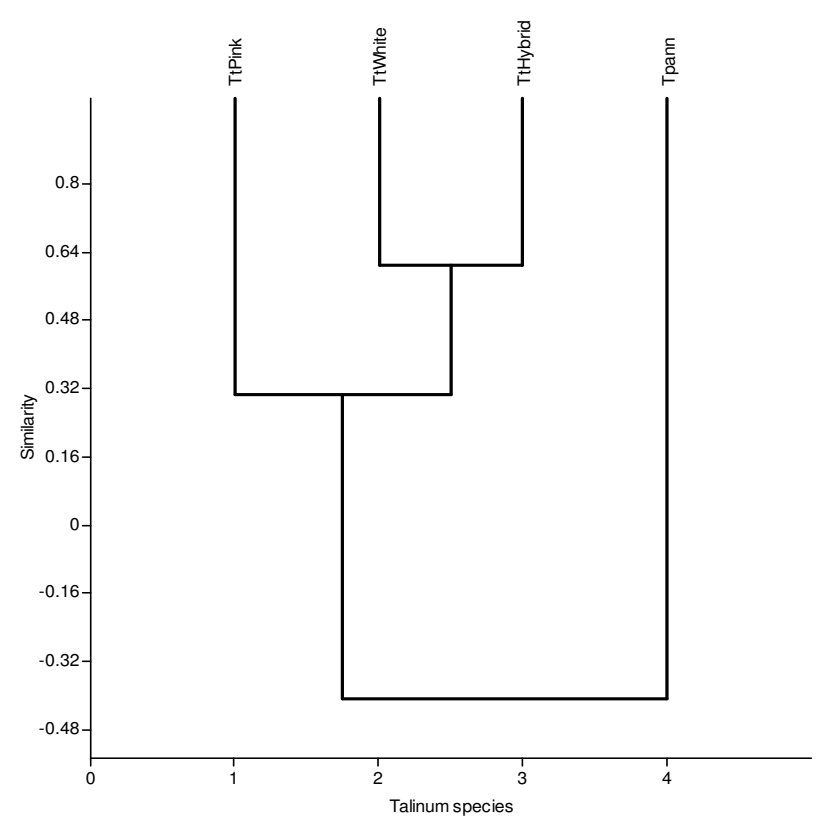

Fig. 1. Single Linkage Cluster Analysis (SCLA) dendrogram of the taxa of Talinum studied using the quantitative and qualitative pollen characters. Legend: TtPink - Talinum triangulare Pink Petals; TtWhite - Talinum triangulare White Petals; TtHybrid - Talinum triangulare Pink and White Petals F1 Hybrid; Tpann - Talinum paniculatum

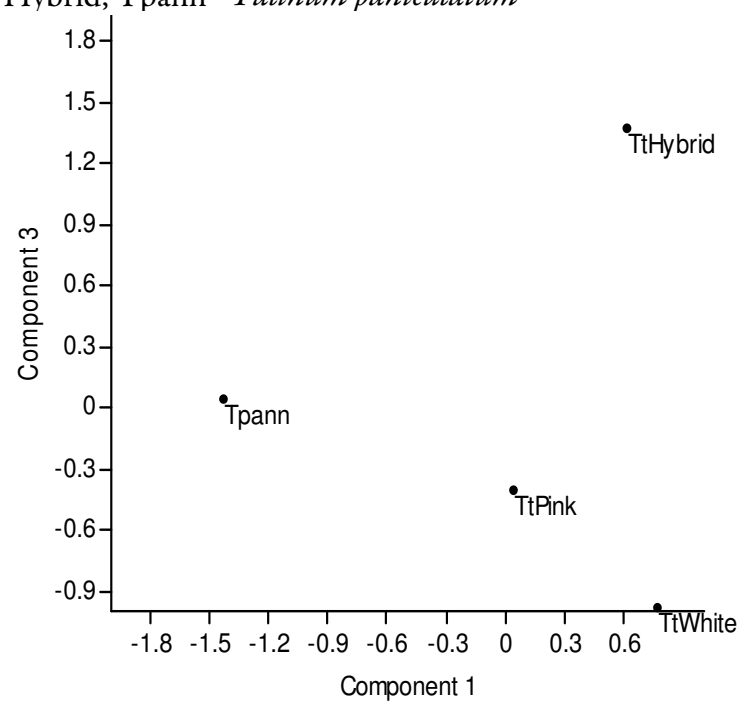

Fig. 3. Principal Component Analysis showing the relationship of Talinum taxa based on ten quantitative and qualitative pollen characters. Legend: TtPink - Talinum triangulare Pink Petals; TtWhite - Talinum triangulare White Petals; TtHybrid - Talinum triangulare Pink and White Petals F1 Hybrid; Tpann - Talinum paniculatum

\section{Talinum paniculatum}

The pollen units are monads and are majorly circular in shape but occasionally ovate or quadrangular. The pollen grain types are acolpate, monocolpate, tricolpate, tetracolpate and pentacolpate (Fig. 4). The mean diameter of the pollen grains was $44.87 \pm 0.26 \mu \mathrm{m}$. The pollens have an average of $5.51 \pm 0.07$ number of pores.

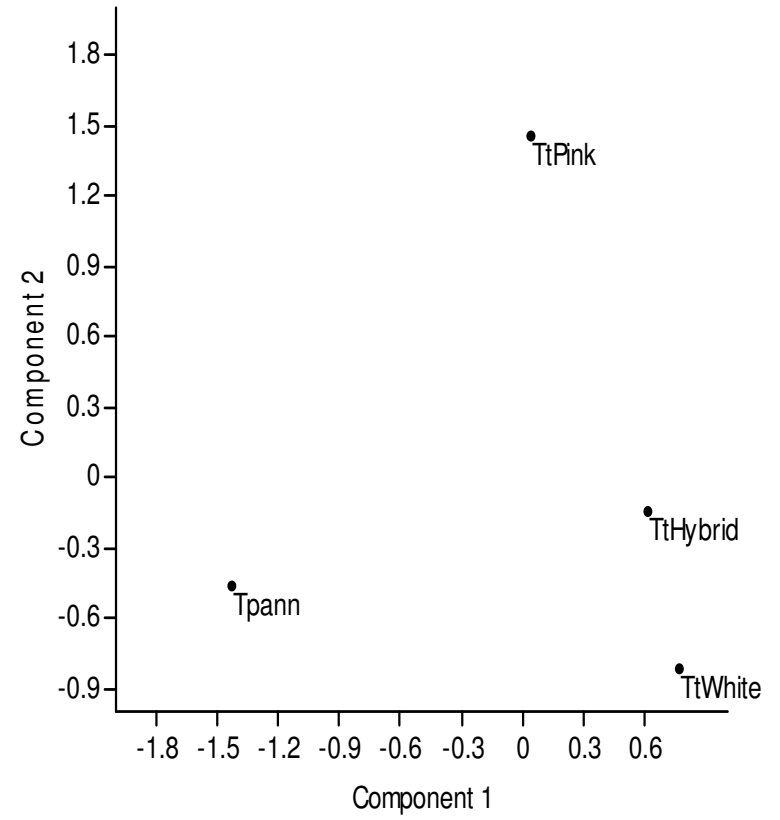

Fig. 2. Principal Component Analysis showing the relationship of Talinum taxa based on ten quantitative and qualitative pollen characters. Legend: TtPink - Talinum triangulare Pink Petals; TtWhite - Talinum triangulare White Petals; TtHybrid - Talinum triangulare Pink and White Petals F1 Hybrid; Tpann - Talinum paniculatum

\section{T. triangulare pink petals}

The pollen units are monads and are majorly circular in shape but occasionally ovate. The pollen grain types are acolpate, monocolpate and tetracolpate (Fig. 5). The mean diameter of the pollen grains was $59.34 \pm 0.42 \mu \mathrm{m}$. The pollens have an average of $12.71 \pm 0.11$ number of pores.

\section{T. triangulare whitepetals}

The pollen units are monads and dyads. They are majorly circular in shape but occasionally ovate. The pollen grain types are acolpate, monocolpate and tricolpate (Fig. 6). The mean diameter of the pollen grains was $61.52 \pm 0.54$ $\mu \mathrm{m}$. The pollens have an average of $13.22 \pm 0.12$ number of pores.

\section{T. triangulare pink petal and white petal F1 hybrid}

The pollen units are monads and dyads. They are majorly circular in shape but occasionally ovate. The pollen grain types are acolpate, monocolpate and bicolpate (Fig. 7). The mean diameter of the pollen grains was $58.83 \pm 0.36$ $\mu \mathrm{m}$. The pollens have an average of $13.47 \pm 0.11$ number of pores. From the result of the Single Linkage Cluster Analysis, the taxa of Talinum in this study were clustered into two main groups. The two varieties of $T$. triangulare and their F1 hybrid clustered together in the first grouping, clearly separated from $T$. paniculatum. In the second grouping, $T$. triangulare pink petal was separated leaving $T$. triangulare white petals and the F1 hybrid clustered together. This agrees with the result of the Principal Components Analysis when components one and two were used. When components one and three were used, $T$. paniculatum was still from the other taxa of $T$. triangulare. 

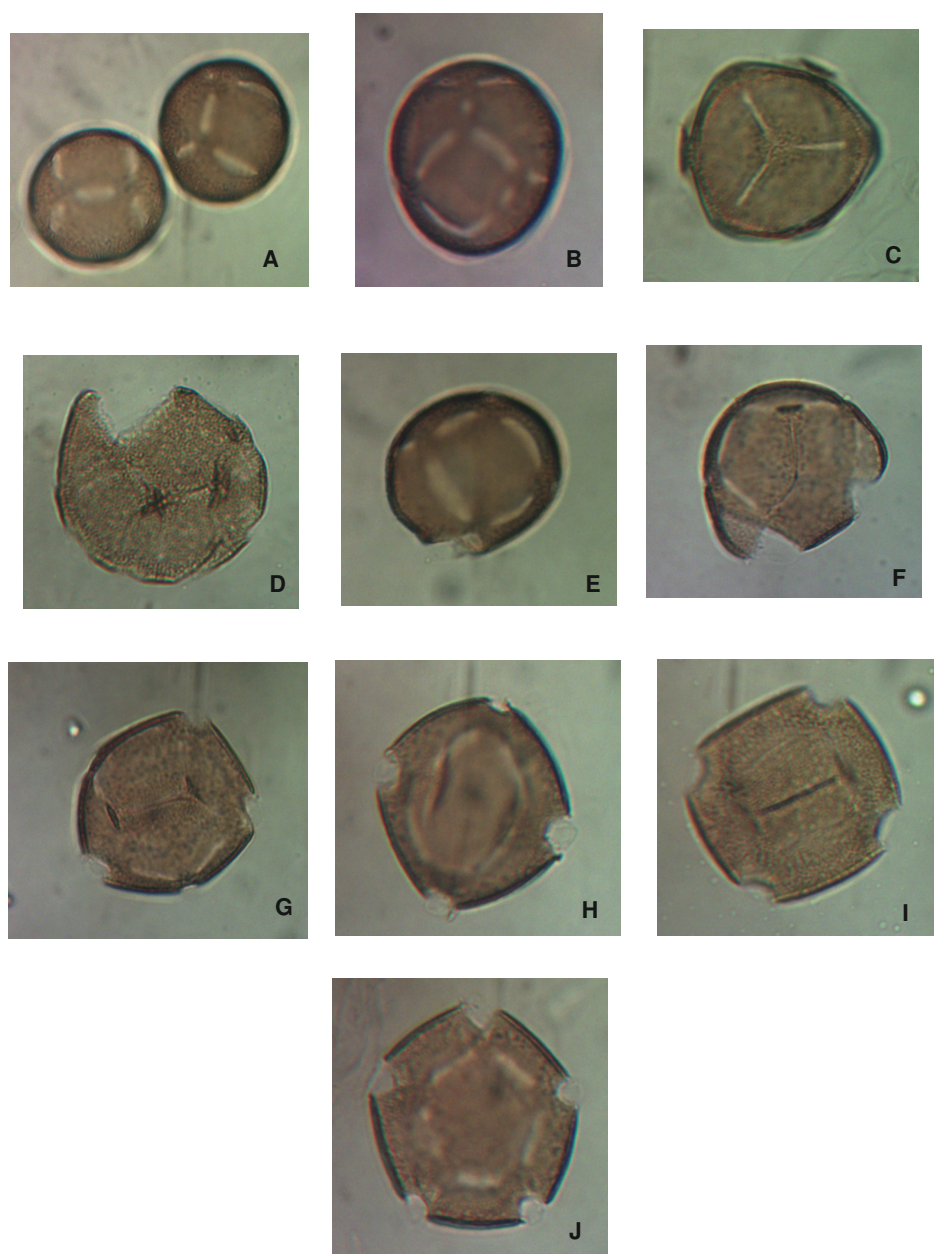

Fig. 4. Pollen grains of T. paniculatum (×400) A - C. Acolpate, D \& E. Monocolpate, F. Bicolpate, G. Tricolpate, H \& I. Tetracolpate J. Pentacolpate
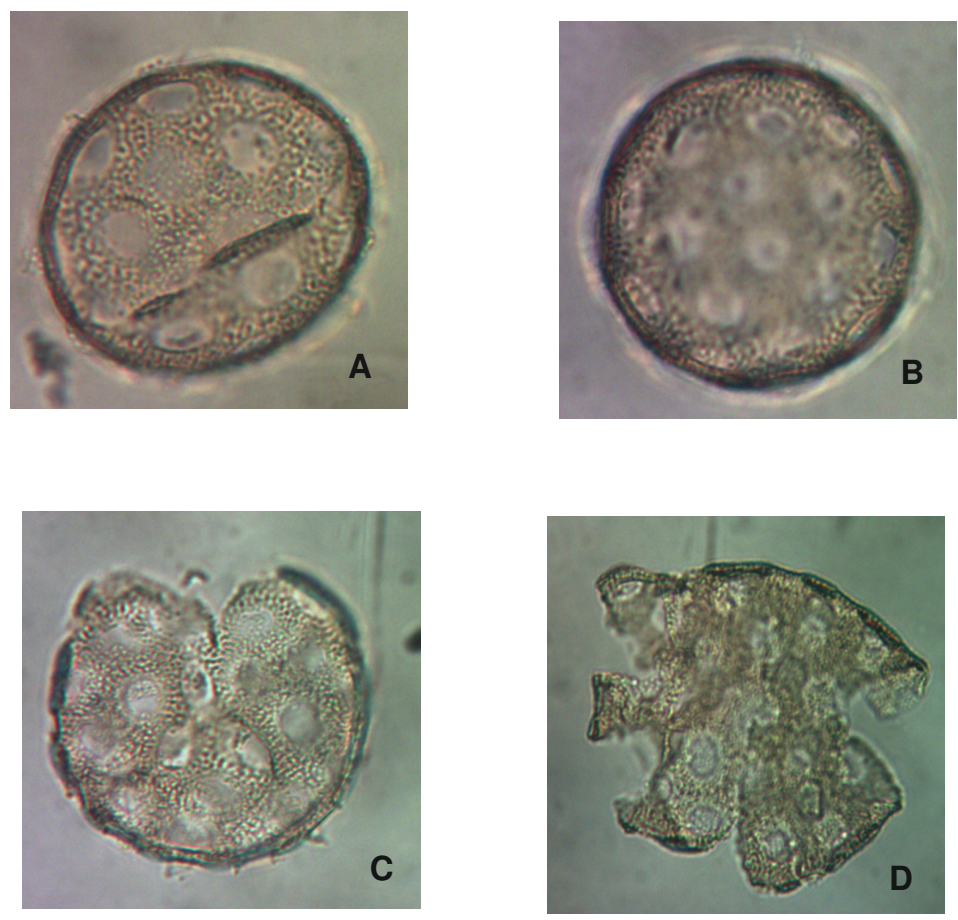

Fig. 5. Pollen grains of T. triangulare pink petals (×400) A \& B. Acolpate, C. Monocolpate, D. Tetracolpate 

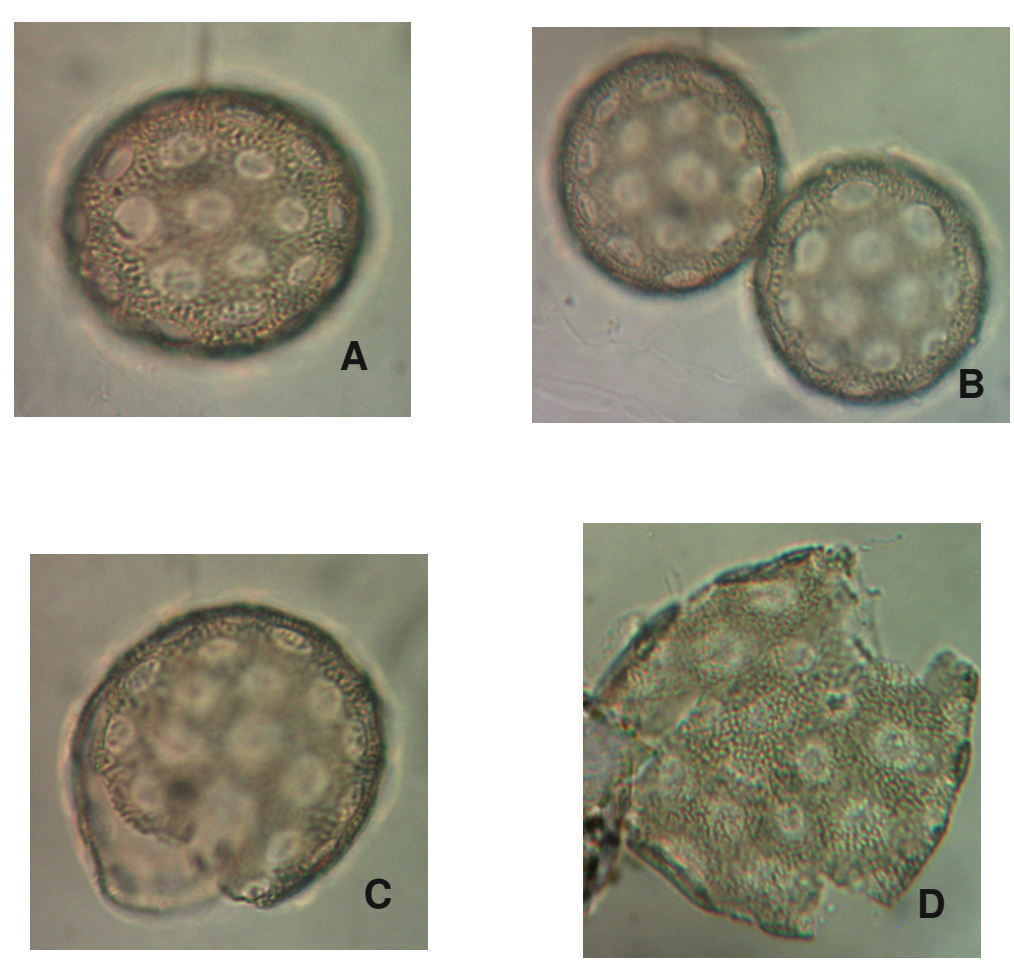

Fig. 6. Pollen grains of T. triangulare white petals (×400) A. Acolpate, B. Dyad pollens, C. Monocolpate, D. Tricolpate
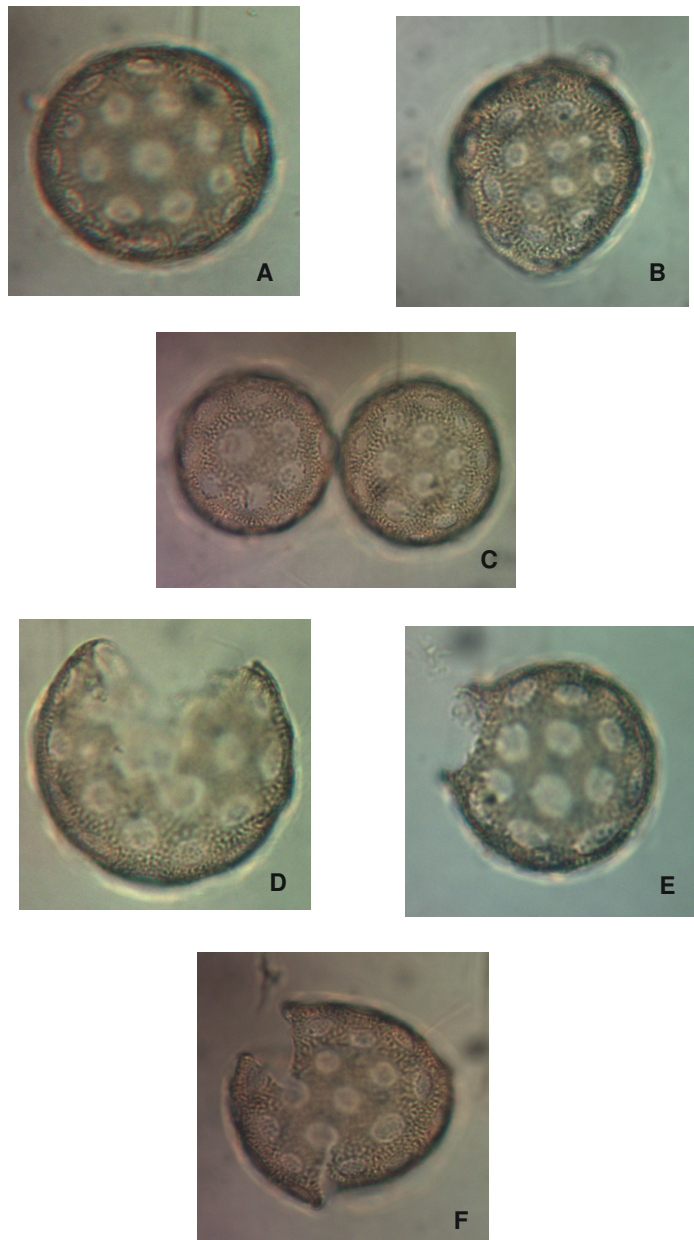

Fig. 7. Pollen grains of T. triangulare pink and white petal F1 hybrid (×400) A \& B. Acolpate, C. Dyad pollens, D \& E. Monocolpate, F. Bicolpate 
180

\section{Discussion}

The pollens of the four taxa in this study are similar in most of their attributes which include monad pollen units, circular and ovate pollen shapes as well as the presence of acolpate and monocolpate pollen grains in all the taxa studied. Yet, there are a few characters that can still be employed in separating them. Pollen unit is one of such, in that, though all the taxa had their pollens shed as monads, additional dyad pollen units, were encountered in $T$. triangulare white petal and the F1 hybrid. This is a rare occurrence in angiosperms as pointed out by Simpson (2010) and according to Pacini and Franchi (1999), gymnosperms and angiosperms pollens are shed as monads, tetrads, polyads, massulae or compact pollina. Quadrangular pollen shape is also unique to $T$. paniculatum as an additional type of pollen shape to the circular and ovate shapes common to all the taxa. This is also useful in delimitating the taxa.

Based on the aperture (colpi) types, the pollen grains present in the genus Talinum are acolpate, monocolpate, bicolpate, tricolpate, tetracolpate and pentacolpate. Apertures function mainly as sites where pollen tubes are formed. They also allow changes in the volume of pollen which is influenced by changes in their water content (Simpson, 2010). All the taxa in this study have acolpate and monocolpate pollen grains which imply that these two aperture types are generic. Notwithstanding, specific pollen grains present in just one or two of the taxa can be employed in separating them. Tricolpate, tetracolpate and pentacolpate pollen grains are the additional pollen types in $T$.paniculatum, which gives the species the highest diversity in terms of pollen grain aperture and the most advanced in the evolutionary development. Adedeji (2005) and Arogundade and Adedeji (2009) attributed higher colpi number to advanced evolutionary development. Tricolpate pollens were encountered in T. triangulare white petals as additional pollen type while tetracolpate pollen grains were encountered in $T$. triangulare pink petals as the additional type. The only additional type of pollen grain encountered in the hybrid, $T$. triangulare F1 hybrid but not present in either of the parent plants is the bicolpate pollen type. Also worthy of note on the aperture is the shape of the pores in the four taxa of Talinum studied. The pores on the pollen are longer than broad in $T$. paniculatum while they are usually circular in the three taxa of $T$. triangulare. The pore shape can thus be employed in delimiting the taxa.

The pollens of the T.triangulare varieties and hybrid are bigger in size than those of $T$. paniculatum and this was confirmed by the Duncan Multiple Range Test shows a significant difference among them. Erdtman (1952) made a valid contribution in terms of pollen grain size classification which is still very relevant. Based on his classification, the pollens of T.paniculatum are Media, that is, pollen diameter of between $25 \mu \mathrm{m}$ and $50 \mu \mathrm{m}$ while those of the two varieties of $T$. triangulare and their F1 hybrid are Magna, pollen diameter of between $50 \mu \mathrm{m}$ and $100 \mu \mathrm{m}$.

A review of the quantitative characters of the pollen reveals that there are no significant differences in the pore diameter and number of pores of $T$. talinum white petals and the F1 hybrid. For the pollen diameter, there is no significant difference between the F1 hybrid and $T$. triangulare pink petals. The F1 hybrid of $T$. triangulare pink petals and $T$. triangulare white petals have specific characteristics or traits that are similar to either of the parent plants. It is also important to note the shape of the pores on $T$. paniculatum which are longer than wide as opposed to the circular or elliptic pore shapes encountered in the varieties and hybrid of T. triangulare. The first three components of the PCA accounted for the total variation among the taxa in this study. From component one, the pollen shape, pentacolpate pollen aperture, pore diameter and number of pores were the characters responsible for the variation, pollen wall thickness was responsible for the variation based on component two while bicolpate and tricolpate pollen apertures were responsible for the variation based on component three.

\section{Conclusions}

The taxa of Talinum in this study have generic features which support their classification as a genus as well as distinct features which ascertain their individuality. These distinct features which are dyad pollen units, quadrangular pollen shape, bicolpate, tetracolpate and pentacolpate pollen grains as well as pollen size and pore shape can be employed as diagnostic tools in the delimitation of the species, varieties and the hybrid.

\section{References}

Adedeji O (2005). Pollen morphology of the three species of the genus Emilia Cass. (Asteraceae) from Nigeria. Thaiszia Journal of Botany 15:1-9.

Akinwusi O, Illoh HC (1996). Pollen grain morphology of some species of Hibiscus Linn. Nigerian Journal of Botany 9:9-14.

Arogundade OO, Adedeji O (2009) Pollen grain morphology of three species and a variety of Ocimum Linn. (Lamiaceae) in Southwestern Nigeria.Journal of Science and Technology 29(3):1-7.

Brasileiro BG, Barbosa JB, Jamal CM, Coelho OGL, Ronchi R, PizzioloVR (2016). Anatomical characterization, chemical composition and cytotoxic activit of Talinum triangulare (Jacq.) Willd (Portulacaceae). CiênciaeNatura 38(2):665-674.

Edeoga RO, Ugbo RN, Osawe PI (1998). Palynomorphology of species of Commelina L. and Senna Toum. Ex. Mill. from Nigeria. New Botanist 25:1-10.

Ekpo IA, Osuagwu AN, Okpako EC, Agbor RB, Ekanem BE (2013). Physicochemical and morphological features of Talinum triangulare (water-leaf) exposed to hydrocarbon polluted soil. Global Journal of Biodiversity Science and Management 3(1):52-57.

Erdtman G (1952). Pollen morphology and plant taxonomy of Angiosperms. Almqvist and Wiksell, Stockholm.

Erdtman G (1960). The acetolysis method in a revised description. Svensk Botanisk Tidskrift Lund 54(4):561-564

Hutchinson J, Dalziel JM (1954). Flora of West Tropical Africa. Second Edition, Volume I Part I. White Friars Press, London.

Nya EJ, Eka MJ (2015). Morphological characterization and hybridization of Talinum Triangulare land races for desirable metric characters in 
South Eastern Nigeria. The International Journal of Science and Technology 3(7):192-197.

Nyffeler R, Eggli U (2010). Disintegrating Portulacaceae: A new familial classification of the suborder Portulacineae (Caryophyllales) based on molecular and morphological data. Taxon 59(1):227-240.

Nyananyo BL, Olowokudejo JD (1986). Taxonomic studies in the genus Talinum (Portulacaceae) in Nigeria. Willdenowia 15(2):455-463.

Nyananyo BL (1992). Pollen morphology in the Portulacaceae (Centrospermae). Folia Geobotanical et Phytotaxonomica 27(4):387400.

Ozeigbe M, Faluyi JO, Idowu, JA (2012). Inheritance of pigmentation patterns in Talinum triangulare (Jacq.) Willd. Ife Journal of Science 14(2):363-367.

Pacini E, Franchi GG (1999). Pollen grain sporoderm and types of dispersal units. ActaSocietatis Botanicorum Poloniae 68(4):229-305.
PuntW, Hoen, PP, Blackmore S, Nilsson S, Le Thomas A (2007). Glossary of pollen and spores terminology. Review of Palaeobotany and Palynology 143(1-2):1-81.

Simpson MG (2010). Plant systematics. Second edition. Academic Press, Amsterdam.

Swarna J, Ravindhran R, Lokeswari TS (2015). Characterization of Talinum triangulare (Jacq.) Willd. germplasm using molecular descriptors. South African Journal of Botany 97:59-68.

Veselova TD, Dzhalilova KK, Remizowa MV, Timonin AC (2012). Embryology of Talinum paniculatum (Jacq.) Gaertn. and T. triangulare (Jacq.) Willd. (Portulacaceae s.l, Caryophyllales). Wulfenia 19:107-129.

Wagner WL, Herbst DR (2003). Supplement to the manual of the flowering plants of Hawaii. University of Hawaii Press, Hawaii. 